\title{
Effect of Prescriber Education on the Use of Medications Contraindicated in Older Adults in a Managed Medicare Population
}

\author{
MICHELE B. KAUFMAN, PharmD; KALIROI ALIMONOS BRODIN, PharmD; and ARAKSI SARAFIAN, BSPharm, MS
}

\begin{abstract}
OBJECTIVE: To measure the effect of pharmacy intervention programs on the percentage of older adult members filling prescriptions for one or more contraindicated medications in a managed Medicare population.

METHODS: Prescribers of potentially inappropriate (i.e., contraindicated) medications in a managed Medicare + Choice (now known as Medicare Advantage) health maintenance organization (HMO) were identified from drug claims each calendar quarter for letter and telephone contact. The initial study population was composed of members in the Medicare + Choice HMO who were aged 65 years or older and who utilized their managed care pharmacy benefit during the 4-year measurement period from 1999 fourth quarter (Q4) through 2003 Q4. The study population was expanded in 2003 Q1 to include all patients aged 65 years or older, including commercial HMO members and Medicare + Choice members. The prescribers of target (contraindicated) drugs were contacted by a letter that described the program and included a prescriber-specific list of patients who had received a potentially inappropriate drug. Each prescriber was requested to review the report and change the contraindicated drug to a more appropriate agent, lower the medication dose, or carefully monitor those patients who could not discontinue the drug. A clinical pharmacist contacted high-volume prescribers of target drugs (4 or more patients in a given quarter) by telephone to discuss the identified patients.
\end{abstract}

RESULTS: The incidence of inappropriate use of the target medications in older adults declined by $19 \%$, from an absolute $5.3 \%$ of prescriptions in the base period (1999 Q4) to 4.3\% at the end of the first 2-year period, in 2001 Q4. A change in the target drugs in 2002 Q1 from a list based upon the Beers' criteria to a list based in part on the Zhan et al. criteria was associated with a $45 \%$ reduction in the percentage (2.4\%) of older adult members who received target drugs; this proportion remained essentially unchanged at 2.2\% through 2003 Q4, the end of the second half of the 4-year intervention period.

CONCLUSIONS: A clinical intervention program targeting prescribers of drugs judged to be contraindicated in older adults was associated with a decline in the percentage of $\mathrm{HMO}$ members receiving one or more target contraindicated drugs. After a 4-year intervention period, $2.2 \%$ of older adult HMO members continued to receive one or more target contraindicated drugs.

KEYWORDS: Geriatrics, Drugs, Adverse drug reactions, Physician prescribing, Contraindicated drugs, Pharmacy intervention, Pharmacy case management

J Manag Care Pharm. 2005;11(3):211-19

Authors

MICHELE B. KAUFMAN, PharmD, is a project leader for clinical pharmacy programs, KALIROI ALIMONOS BRODIN, PharmD, is director of clinical ph a rmacy programs, and ARAKSI SARAFIAN, BSPharm MS, is vice president, ph a rmacy services department, HIP Health Plan of New York, New York City.

AUTHOR CORRESPONDENCE: Michele B. Kaufman, PharmD, Project Leader, Clinical Pharmacy Programs, HIP Health Plan of New York, 55 Water Street, 12th Fl. South, New York, NY 10041. Tel: (646) 447-7192; Fax: (646) 447-3061; E-mail: MKaufman@HIPUSA.com

Copyright $\odot$ 2005, Academy of Managed Care Pharmacy. All rights reserved.
A s people age, they develop medical conditions that are often treated with pharmaceuticals. Additionally, as people age, pharmacokinetic and pharmacodynamic changes occur that can affect the disposition of medications in the body ${ }^{1}$; this combination of pharmacokinetic and pharmacodynamic changes as well as an increase in medical conditions requiring drug treatment can lead to increased risks of drug interactions, noncompliance, and adverse outcomes in older adult patients. There are numerous case reports and review articles in the medical literature that document serious drugrelated morbidity and/or deaths related to medication use in older adults. ${ }^{2-8}$ Some of these drug effects are direct extensions of the drug's own pharmacologic effect, such as increased sedation from a sedative-hypnotic agent or hypotension from antihypertensive agents, while other effects can be due to adverse outcomes resulting from a particular agent or class of agents (e.g., falls related to use of long-acting benzodiazepines). ${ }^{3-5}$

In the early 1990s, Beers identified medications that were deemed inappropriate to use for nursing home residents. Subsequently, Beers developed explicit criteria to determine potentially inappropriate medication use in noninstitutionalized older adults (65 years or older). ${ }^{9}$ Beers defined inappropriate medications as those agents where the potential risk of use outweighs the potential benefit. Subsequently, Zhan et al. addressed the limitations of Beers's research by identifying criteria for 33 drugs/drug classes based on whether the drug should always be avoided in older adults or whether use of the drug may be appropriate in older adult patients under certain circumstances. ${ }^{2}$ The agents that were identified were placed into 3 categories: (1) drugs that should generally be avoided in ambulatory older adult patients, (2) doses or frequencies of drug administration that generally should not be exceeded, and (3) medications that should be avoided in older people known to have any of several medical conditions. The compete list of d rugs identified by Zhan et al. can be found in their publication. ${ }^{2}$

Willcox et al. examined the amount of inappropriate drug prescribing in community-dwelling patients older than 65 years from the 1987 National Medical Expenditure Survey. ${ }^{10}$ Criteria for inappropriate medications were developed through a modified Delphi consensus technique by a panel of 13 experts in pharmacology and geriatrics. The consensus panel defined as inappropriate any medications that should be entirely avoided, excessive dosage of medicines, and excessive duration of treatment. The list of medications used by the consensus panel was limited to 23. Using a subset of these drugs ( $n=20$, excluding the antihypertensives propranolol, methyldopa, and reserpine), they 
found that $23.5 \%$ of all community-dwelling seniors, or 6.64 million people, received at least 1 potentially inappropriate medication during 1987. When they evaluated the entire list of 23 drugs, they found that $32 \%$ of all elderly people, or 9.04 million community-dwelling seniors, received at least 1 potentially inappropriate medication. They also found that the rare instances where some of the contraindicated medications "may be appropriate" accounted for almost none of their use. Additionally, they did not consider drug dosage, duration, or medication interactions. Although their data were consistent with other studies of inappropriate prescribing for nursing home residents and the incidence of self-reported adverse drug effects in community-dwelling seniors, the authors felt that the numbers of community-dwelling seniors who received at least 1 inappropriate medication was disturbingly high.

Stuck et al. investigated the prevalence of inappropriate medication use in community-dwelling older persons ( 75 years and older) by using in-home interviews with study subjects regarding medication use. ${ }^{11}$ Inappropriate medication use was evaluated using explicit criteria developed through the modified Delphi consensus process. A total of 414 community-dwelling persons participated in the study, and the mean patient age was 80.5 years in a range of 75 to 95 years. Overall, they found that $6.9 \%(n=69)$ of all reported prescription medications were inappropriate according to their criteria. These 69 inappropriate medications were used by 58 (14\%) of the 414 subjects, with 49 (11.8\%) reporting the use of 1 medication, and 9 (2.1\%) reporting the use of 2 or more inappropriate medications. The most commonly used medications included the long-acting benzodiazepines, dipyridamole, amitriptyline, or chlorpropamide. The authors noted that since older individuals may underreport the number of medications that they are actually taking by as much as $20 \%$ to $30 \%$, the amount of medication actually taken may also be significantly underestimated. Thus, the $14 \%$ prevalence of inappropriate medication use reported here is likely much lower than the actual percentage.

Goulding studied trends in inappropriate prescribing in ambulatory older adult patients using data from 1995 through 2000. ${ }^{12}$ Data were reviewed from office-based physician visits in the National Ambulatory Medical Care Survey and the hospital outpatient departments of the National Hospital Ambulatory Medical Survey. Drugs were identified from Beers's and Zhan's criteria. ${ }^{2,9}$ She concluded that, in the time frame studied, at least 1 potentially inappropriate medication (by the Beers criteria) was prescribed $7.8 \%$ of the time, and at least 1 potentially inappropriate medication (by the Zhan et al. criteria) was prescribed $3.7 \%$ to $3.8 \%$ of the time. Pain relievers (propoxyphene) and central nervous system drugs (anxiolytics, sedative/hypnotics, and antidepressants) were the most commonly prescribed drugs. She also observed that (1) women were at higher risk than men to receive a potentially inappropriate medication, possibly due to more inappropriate prescribing at physician's office visits for central nervous system agents and pain relievers or because studies show that women are prescribed more psychotropic medications compared with men and (2) prescribing of potentially inappropriate medications was mostly done by general practitioners rather than specialists. The author noted that use of these medications in this patient population still occurs and is still inappropriate and that quality improvement efforts should be performed to correct prescribing of inappropriate medications in this patient population. She also noted that more comprehensive drug and diagnosis data would assist in truly determining the inappropriateness of drug prescribing in this patient population.

In 2004, Curtis et al. concluded that $21.2 \%$ of patients 65 years or older in a large outpatient pharmacy benefit management population received one or more "drugs of concem" using updated Beers criteria. ${ }^{13}$ This analysis was limited to 18 medications from a retrospective claim review performed during 1999. They noted that psychotropic drugs alone accounted for more than $45 \%$ of the claims for medications on the Beers list. They concluded that since these potentially inappropriate medications continue to be prescribed, patients should be closely monitored.

Prescribing potentially inappropriate (i.e., contraindicated) medications represents an area of concern in the delivery of medical care, especially in older individuals. It can lead to mortality, morbidity, and increased costs of care. As the medical literature continues to expand on this topic, there is still a need to evaluate specific populations of older patients. We reported our intervention project for prescribers of potentially inappropriate drugs in older adults to the Centers for Medicare and Medicaid Services at the time of their 2000 site visit to our health maintenance organization (HMO). The Centers for Medicare and Medicaid Services encourages the conduct of perfomance improvement projects that achieve, through ongoing measurement and interventions, demonstrable and sustained improvements in important aspects of patient care. This intervention is also one of the many examples of "Patient Safety" reported by HIP Health Plan of New York (HIP-NY) to the National Committee for Quality Assurance as part of the accreditation survey in 2001 and again in 2004. Therefore, evaluation of our Medicare and/or older adult members appeared to be a warranted and necessary activity. Our goal was to reduce the percentage of older adult members filling prescriptions for one or more contraindicated medications to as low a level as possible.

\section{Methods}

\section{Study Population and Design}

This analysis was performed using a large database of paid electronic pharmacy claims from HIP-NY. This is a not-for-profit, mixed-model HMO serving more than 1.4 million members. Approximately 110,000 members were Medicare beneficiaries in 2004, up from approximately 91,000 Medicare risk members 
Effect of Prescriber Education on the Use of Medications Contraindica ted in Ol der Adults in a Man aged Medicare Population

\section{TABLE 1 List of Contraindicated (Target) Drugs in This HMO Intervention Program}

\begin{tabular}{|c|c|c|c|}
\hline Generic Name & Reason for Contraindication & 1999 Through $2001^{*}$ & 2002 Q1 to Present $\dagger$ \\
\hline Amitriptyline & Anticholinergic_-sedation, orthostatic hypotension & $\sqrt{ }$ & $\sqrt{ } \neq$ \\
\hline Cyclobenzaprine & $\begin{array}{l}\text { Poorly tolerated, anticholinergic-sedation, CNS effects } \\
\text { (benefit does not outweigh risk) }\end{array}$ & $\sqrt{ }$ & $\sqrt{ }$ \\
\hline Diazepam & Daytime sedation, increased "fall" risk & $\sqrt{ }$ & $\sqrt{ }$ \\
\hline Dicyclomine & Anticholinergic—sedation, blurred vision, confusion, constipation & & $\sqrt{ }$ \\
\hline Disopyramide & $\begin{array}{l}\text { Anticholinergic-sedation; may exacerbate glaucoma, urinary retention, } \\
\text { and benign prostatic hypertrophy; safer alternatives are available }\end{array}$ & & $\sqrt{ }$ \\
\hline Hyoscyamine & Anticholinergic—sedation, blurred vision, confusion, constipation & & $\sqrt{ }$ \\
\hline Indomethacin & More CNS toxic than other NSAIDs, greater bleed risk & $\sqrt{ }$ & $\sqrt{\S}$ \\
\hline Meprobamate & Highly addictive; need to slowly withdraw & $\sqrt{ }$ & $\sqrt{ }$ \\
\hline Methocarbamol & $\begin{array}{l}\text { Poorly tolerated, anticholinergic-sedation, CNS effects } \\
\text { (benefit does not outweigh risk) }\end{array}$ & $\sqrt{ }$ & $\sqrt{ }$ \\
\hline Methyldopa & May cause bradycardia and exacerbate depression & $\sqrt{ }$ & $\sqrt{ }$ \\
\hline $\begin{array}{l}\text { Propoxyphene } \\
\text { combinations }\end{array}$ & Offers few analgesic advantages; may cause CNS and cardiac toxicity & $\sqrt{ } \|$ & \\
\hline
\end{tabular}

* Modified from: Beers MH. Explicit criteria for determining potentially inappropriate medication use by the elderly. Arch Intern Med. 1997;157:1531-36.

† Modified from: Zhan C, Sangl J, Bierman AS, et al. Potentially inappropriate medication use in the community-dwelling elderly. JAMA. 2001:286:2823-29.

\$Doses $>50$ mg per day.

$\S$ Chronic users of indomethacin (defined as 2 or more prescriptions for indomethacin in the calendar quarter)

II Included: propoxyphene, propoxyphene/acetaminophen, propoxyphene/aspirin/caffeine, propoxyphene napsylate, propoxyphene napsylate/acetaminophen.

CNS = central nervous system; HMO=health maintenance organization; NSAIDs=nonsteroidal anti-inflammatory drugs.

in 2000 quarter (Q) 1. The Pharmacy Services Department of the HMO functions as its own pharmacy benefit manager (PBM). For this study, pharmacy claims that were reversed were identified and excluded from analysis to prevent false-positive letters to prescribers.

The study population consisted of Medicare beneficiaries who utilized their HMO pharmacy benefit to obtain medications during the measurement periods. The target population was expanded in 2003 Q1 to include commercial HMO members aged 65 years and older. In other words, the pool of patients subject to the intervention program was expanded from members with a Medicare + Choice (now known as Medicare Advantage) drug benefit rider to include members aged 65 years or older enrolled in commercial HMO plans.

A prospective study approach was used to identify older adult members who received one or more prescriptions for potentially inappropriate medications. At the beginning of the program (1999), an initial list of 8 target (contraindicated) medications was identified from the literature..$^{8,914}$ Two of the HIP-NY clinical pharmacists determined the initial list of medications based on actual pharmacy claims and review of the literature (the Beers list and that of the U.S. General Accounting Office [July 1995] report on Prescription Drugs and the Elderly, which identified the following drugs as potentially harmful in older adults: amitriptyline, indomethacin, cyclobenzaprine, propoxyphene, diazepam, meprobamate, methocarbamol, methyldopa, hyoscyamine, dicyclomine, and disopyramide). ${ }^{14}$ The recommendations were reviewed and approved by our pharmacy and therapeutics committee. Additionally, due to decreased utilization and attempts to revise the HMO's drug formulary to reflect more appropriate medications for use in older adults, the following changes were implemented: deletion of flurazepam, meprobamate, chlorpropamide, and methyldopa, and addition of oxazepam.

In 2002 Q1, we updated our target medication list based on our actual pharmacy claims and information published by Zhan et al. At that time, the target list of drugs was expanded from 8 to 10 with the addition of dicyclomine, hyoscyamine, and disopyramide and the removal of propoxyphene (Table 1). Other program modifications at this time included targeting only (1) chronic users (patients who had more than 1 claim in a quarter) of indomethacin and (2) patients who received more than $50 \mathrm{mg}$ of amitriptyline per day. These modifications were based on new medical literature (Zhan et al. ${ }^{2}$ ) and physician input. According to Zhan et al., amitriptyline may be appropriate for some indications in older adults, and provider feedback from interventions suggested that lower doses of amitriptyline were not being used for depression but for such conditions as pain management and diabetic neuropathy with appropriate follow-up and monitoring. ${ }^{2}$ We therefore modified the report to target amitriptyline in doses greater than $50 \mathrm{mg}$ daily. Zhan et al. also stated that indomethacin may be appropriate for short 
courses (e.g., acute gouty arthritis) and implied that chronic use is not recommended. Therefore, we chose to target chronic users of indomethacin, defined as more than 1 pharmacy claim for indomethacin during each intervention quarter.

Regarding the anticholinergic agents disopyramide, cyclobenzaprine, dicyclomine, and methocarbamol, it is generally felt that these agents should be avoided in older adults due to their potential adverse effects. ${ }^{2}$ We also decided to target disopyramide based on our pharmacy utilization and the choices of alternate antiarrhythmic agents. We added dicyclomine and hyoscyamine to our list of targeted medications based on pharmacy utilization and the individual agent's potential for adverse effects in this patient population. We decided to no longer target propoxyphene due to decreased pharmacy utilization of this agent. Since methyldopa was listed in the Beers criteria, has the potential to cause bradycardia and exacerbate depression in older adults, and was highly utilized in our patient population, we chose to include it as one of our targeted medications. Additionally, there are many alternate treatments for hypertension that have less serious side effects.

We calculated quarterly measurements of the proportion of older adult members who filled a prescription for a contraindicated drug. We also calculated the proportion of older adult members who filled a prescription for 1 or more of the subset of 7 targeted contraindicated drugs that was consistent throughout the entire 4-year intervention period.

This intervention program with prescribers of target contraindicated drugs for older adult members in this health plan is ongoing. The base period for assessing the impact of the intervention program was the fourth calendar quarter (Q4) of 1999. The measurement period for this study included 16 calendar quarters from 2001 Q1 through the 2003 Q4. Letters were mailed to prescribers of medications contraindicated in older patients after the end of each calendar quarter. The letter described the program and included a provider profile (Appendix). In some cases, the prescriber was not the primary care provider (PCP) for the particular patient (the prescriber may have been another PCP or a specialist). Therefore, each prescriber and PCP received a profile containing their names, the full name and HMO identification number of each patient who received contraindicated drugs in that specific quarter, the generic name of the contraindicated drug(s) that each patient received in that quarter as well as the reason for the contraindication, any formulary alternatives (if available), and identification of the physician prescribing each drug. In addition to sending a prescriber-specific profile, a clinical pharmacist contacted some prescribers by telephone.

Each calendar quarter, prescribers with the highest volume of patients receiving the target contraindicated drugs were contacted by telephone. A clinical pharmacist called prescribers to discuss the target patients' drug use and treatment plan. Alternative therapeutic options were generally discussed with the prescriber during these telephone contacts, as were the risks and benefits of the options and age-related pharmacokinetic and pharmacodynamic changes in older patients. The telephone contact also generally included a discussion of the individual patient's other medications if the clinical pharmacy case manager identified any other potential medication-related problems upon reviewing the patient's medication profile. Drug formulary questions or pharmacy benefit questions were also answered at this time.

A third intervention included publication of an article titled "Inappropriate Prescribing in the Elderly" in the HMO's pharmacy and therapeutics newsletter distributed to each physician and pharmacist provider in the HMO network. ${ }^{15}$ In all, physicians in this HMO were contacted by means of 3 approaches: (1) a physician-specific report card of individual older patients with drugs defined as contraindicated, (2) telephone contact with some of the prescribers of these target contraindicated drugs, and (3) general distribution of written materials to all prescribers. Approximately 45 hours of a clinical pharmacist's time was devoted to this intervention program each calendar quarter. An additional 5 to 10 hours of clerical time is also committed to this project each quarter. Costs of supplies and postage are approximately $\$ 230$ per quarter, not including printer cartridges. This project is conducted in-house at HIP-NY. If a project such as this were to be undertaken with outsourced vendors, administrative costs may be higher.

The proportion of older adult patients prescribed one or more inappropriate drugs (number of prescriptions for one or more inappropriate drugs divided by the total number of older adult members with drug utilization) was calculated for the overall plan and reported annually to appropriate committees within HIP-NY. Physicians identified as prescribing the same drugs in 2 consecutive quarters for the same patient ("repeat prescribers") were reported to the HMO Peer Review Committee in the Quality Risk Management Department. The Peer Review Committee (comprising 5 physicians and a nurse) contacts repeat prescribers to identify the rationale for continued contraindicated drug use. At any intervention point that the prescriber provided appropriate rationale for continued use of the medication to either the Peer Review Committee or pharmacy case manager (e.g., was unable to change the medication or lower the dose of medication, had no safer alternatives available, the patient tolerated the medication well and was being continuously monitored), then the name of the patient and the contraindicated drug were logged into a database. Subsequent quarterly evaluations excluded those patients and their respective contraindicated drug(s).

\section{Measurement and Analysis}

Our goal was to have as few as possible older adult patients receiving any of the targeted contraindicated drugs. We were not able, through a literature review, to ascertain an industry 
standard or benchmark that could be applied to this study. Quarterly measurements of the proportion of Medicare + Choice patients receiving one or more contraindicated drugs were calculated; they were expanded in the fourth year of the intervention to include all patients aged 65 years or older. A time series analysis quantified the number of patients who received the targeted contraindicated drugs over time.

\section{Results}

Quarterly data on the percentage of older adult members who received the target contraindicated medications and the percentage of older adult members who received one or more of the subset of 7 contraindicated medications (consistent through the 4-year period) were analyzed using StatGraphics. Based on a time series analysis of the quarterly data, a linear model was determined to be the best-fitting model for both sets of data. Compared with other models, the linear model minimizes the root mean squared error, the mean absolute error, the mean absolute percentage error, the mean error, and the mean percentage error for these sets of data. Data were forecasted for 4 additional quarters using a linear forecasting model, and statistically significant downward trends were detected for both "the percentage of older adult members who received prescriptions for contraindicated medications," (slope $=-0.23$ percentage points, $P<0.001$ ), and the percentage of older adult members who received one or more of 7 contraindicated medications, (slope $=$ -0.14 percentage points, $P<0.001$ ).

Table 2 presents the number and percentage of older adult members who received a prescription for one or more contraindicated medications during each quarter. Figure 1 graphically presents the number of older adult members, prescribers and PCPs targeted (by quarter). Figure 2 presents the percentage of older adult members who filled contraindicated medications by quarter. Table 3 presents the percentage of older adult members who received one or more of the subset of 7 targeted contraindicated drugs that were consistent throughout the 4 -year study period. Figure 3 graphically represents the data in Table 3.

\section{Discussion}

Several researchers have evaluated the use of explicit criteria for identifying potentially inappropriate medication use in older adult patients in many different settings. ${ }^{2,6-9}$ Other researchers have chosen to develop clinical indicators of preventable drugrelated morbidity ${ }^{16,17}$ We chose to focus on specific "inappropriate" drug use that may produce preventable drug-related morbidity in our population of older patients. Using the Beers criteria, Fick et al. showed that patients with potentially inappropriate medications in 1997-1998 had higher costs and utilization. ${ }^{18}$ Our evaluation used modified Beers and Zhan et al. criteria to determine inappropriate medication use in our older adult outpatient population.

\begin{tabular}{|c|c|c|c|}
\hline 느드 & $\begin{array}{l}\text { Percentage of } \\
\text { Who Filled Pre } \\
\text { of All Target } 1 \mathrm{C} \\
\text { From } 1999 \text { Th }\end{array}$ & $\begin{array}{l}\text { Older Adult } \\
\text { scriptions for } \\
\text { ontraindicat } \\
\text { ough } 2003\end{array}$ & $\begin{array}{l}\text { embers } \\
\text { One or More } \\
\text { ) Drugs }\end{array}$ \\
\hline $\begin{array}{l}\text { Measurement } \\
\text { Period }\end{array}$ & $\begin{array}{c}\text { Patients Filling } \\
\text { Contraindicated } \\
\text { Medications }(\%)^{*}\end{array}$ & $\begin{array}{c}\text { Comparison to } \\
\text { Baseline } \\
\text { (\% Change) }\end{array}$ & $\begin{array}{l}\text { Comparison to } \\
\text { Previous } \\
\text { Quarter } \\
\text { (\% Change) }\end{array}$ \\
\hline 1999 Q4 & $2,871 / 54,211(5.3)$ & Baseline & Baseline \\
\hline 2000 Q1 & $3,110 / 60,704(5.1)$ & -3 & -3 \\
\hline 2000 Q2 & $3,106 / 63,342(4.9)$ & -7 & -4 \\
\hline 2000 Q3 & $3,171 / 64,544(4.9)$ & -7 & 0 \\
\hline 2000 Q4 & $3,053 / 66,169$ (4.6) & -13 & -6 \\
\hline 2001 Q1 & $2,732 / 63,663(4.3)$ & -19 & -7 \\
\hline 2001 Q2 & $2,816 / 63,738(4.4)$ & -17 & 3 \\
\hline 2001 Q3 & $2,701 / 62,540(4.3)$ & -18 & -2 \\
\hline 2001 Q4 & $2,713 / 62,883(4.3)$ & -19 & 0 \\
\hline $2002 \mathrm{Ql} \dagger$ & $1,495 / 63,062(2.4)$ & -55 & -45 \\
\hline 2002 Q2 & $1,719 / 62,313(2.8)$ & -48 & 16 \\
\hline 2002 Q3 & $1,605 / 61,492(2.6)$ & -51 & -5 \\
\hline 2002 Q4 & $1,344 / 62,788(2.1)$ & -60 & -18 \\
\hline 2003 Q1 & $1,488 / 68,294(2.2)$ & -59 & 2 \\
\hline 2003 Q2 & $1,538 / 68,823(2.2)$ & -58 & 3 \\
\hline 2003 Q3 & $1,516 / 67,846(2.2)$ & -58 & 0 \\
\hline 2003 Q4 & $1,451 / 66,936(2.2)$ & -59 & -3 \\
\hline \multicolumn{4}{|c|}{$\begin{array}{l}\text { * The denominator is utilizing members, not total enrolled members. } \\
\text { Criteria changed from Beers (Beers MH. Explicit criteria for determining potentially } \\
\text { inappropriate medication use by the elderly. Arch Intern Med 1997;157:1531-36) to } \\
\text { Zahn et al. (Zhan C, Sangl J, Bierman AS, et al. Potentially inappropriate medica- } \\
\text { tion use in the community-dwelling elderly. JAMA 2001:286:2823-29). }\end{array}$} \\
\hline
\end{tabular}

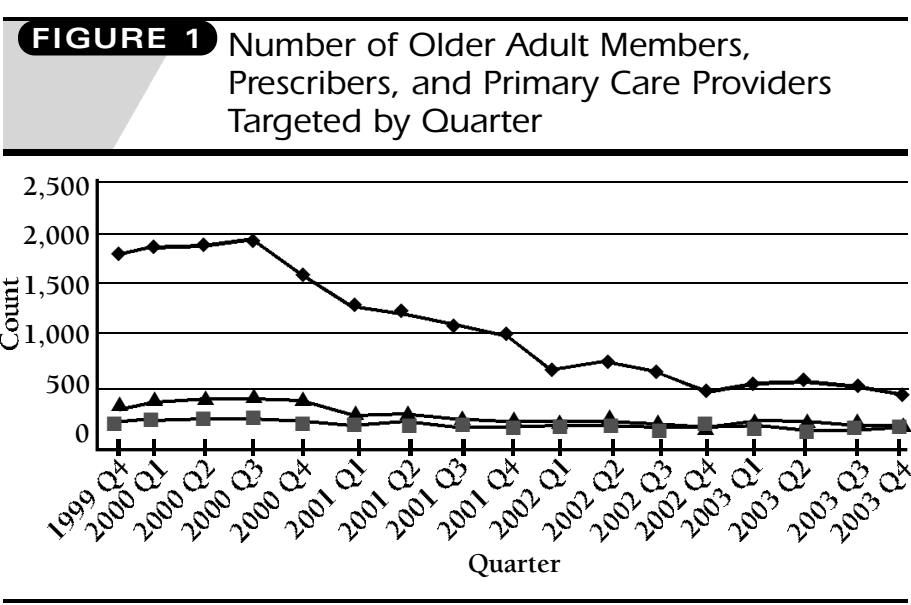

- \# Members Identified \ \# PCPs Targeted a \# Other Prescribers Targeted 


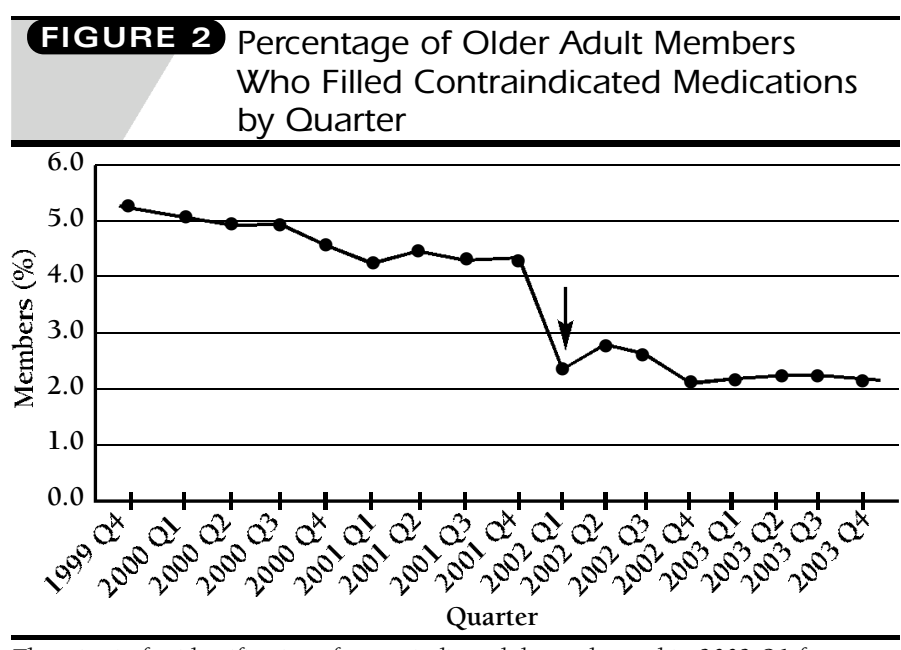

The criteria for identification of contraindicated drugs changed in 2002 Q1 from Beers (Beers MH. Explicit criteria for determining potentially inappropriate medication use by the elderly. Arch Intern Med 1997;157:1531-36) to Zhan et al. (Zhan C, Sangl J, Bierman AS, et al. Potentially inappropriate medication use in the communitydwelling elderly. JAMA 2001:286:2823-29).

In late 2003, Fick et al. updated the Beers criteria for inappropriate medication use in older adults. ${ }^{19}$ Our 7 target drugs were not dropped in the updated Beers criteria, and we have continued to target these 7 medications. Since we must specifically query each prescriber to determine diagnoses, we are not able to address the 2002 criteria for inappropriate medication use according to diagnosis or medical c o n d i t i o $\mathrm{n}$ because we do not have that information readily available to us. Additionally, we have used the updated "inappropriate medication list" presented by Fick et al. to update the "Fomulary Altematives" that we offer to prescribers. We continue to evaluate the new literature to make enhancements to this pharmacy quality initiative.

At the beginning of the intervention program, the most inappropriately prescribed medication was amitriptyline. When the criteria were revised in 2002 Q1 (including the exclusion from the targets of amitriptyline use up to $50 \mathrm{mg}$ per day), cyclobenzaprine became the most common inappropriately prescribed agent. This suggests that low doses of amitriptyline were being used appropriately according to the new criteria but were probably prescribed for off-label uses such as neuropathic pain (e.g., diabetic neuropathy, headache) and urinary incontinence. Throughout the intervention program, the use of skeletal muscle relaxants remained high. At the beginning of the program, cyclobenzaprine was the third most common inappropriately prescribed medication in the program. Diazepam and methocarbamol were also common inappropriately prescribed medications. Prior to the criteria revision in 2002 $\mathrm{Q} 1$, the second most common inappropriately prescribed

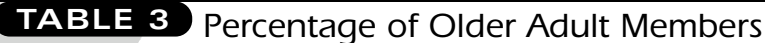 Who Received One or More of Subset (7) Target Contraindicated Drugs}

\begin{tabular}{|c|c|c|c|}
\hline $\begin{array}{l}\text { Measurement } \\
\text { Period }\end{array}$ & $\begin{array}{c}\text { Number Receiving } \\
\geq 1 \text { of } 7 \text { Targeted } \\
\text { Contraindicated } \\
\text { Drugs }\end{array}$ & $\begin{array}{l}\text { Number of } \\
\text { Utilizing } \\
\text { Members* }\end{array}$ & $\begin{array}{c}\text { Percentage of } \\
\text { Patients Who } \\
\text { Received } \geq 1 \text { of } 7 \\
\text { Contraindicated } \\
\text { Medications (\%) }\end{array}$ \\
\hline 1999 Q4 & 1,398 & 54,211 & 2.6 \\
\hline $2000 \mathrm{Q} 1$ & 1,546 & 60,704 & 2.5 \\
\hline 2000 Q2 & 1,525 & 63,342 & 2.4 \\
\hline 2000 Q3 & 1,551 & 64,544 & 2.4 \\
\hline 2000 Q4 & 1,233 & 66,169 & 1.9 \\
\hline 2001 Q1 & 1,037 & 63,663 & 1.6 \\
\hline $2001 \mathrm{Q} 2$ & 1,008 & 63,738 & 1.6 \\
\hline 2001 Q3 & 884 & 62,540 & 1.4 \\
\hline $2001 \mathrm{Q} 4$ & 1,010 & 62,883 & 1.6 \\
\hline 2002 Q1 & 597 & 63,062 & 0.9 \\
\hline 2002 Q2 & 690 & 62,313 & 1.1 \\
\hline 2002 Q3 & 590 & 61,492 & 1.0 \\
\hline 2002 Q4 & 387 & 62,788 & 0.6 \\
\hline $2003 \mathrm{Q1 \dagger}$ & 445 & 68,294 & 0.7 \\
\hline 2003 Q2 & 461 & 68,823 & 0.7 \\
\hline 2003 Q3 & 434 & 67,846 & 0.6 \\
\hline 2003 Q4 & 390 & 66,936 & 0.6 \\
\hline
\end{tabular}

* Number of members who received one or more prescriptions for any drug during the measurement period.

† Intervention program expanded to include commercial plan members as well as Medicare+Choice members.

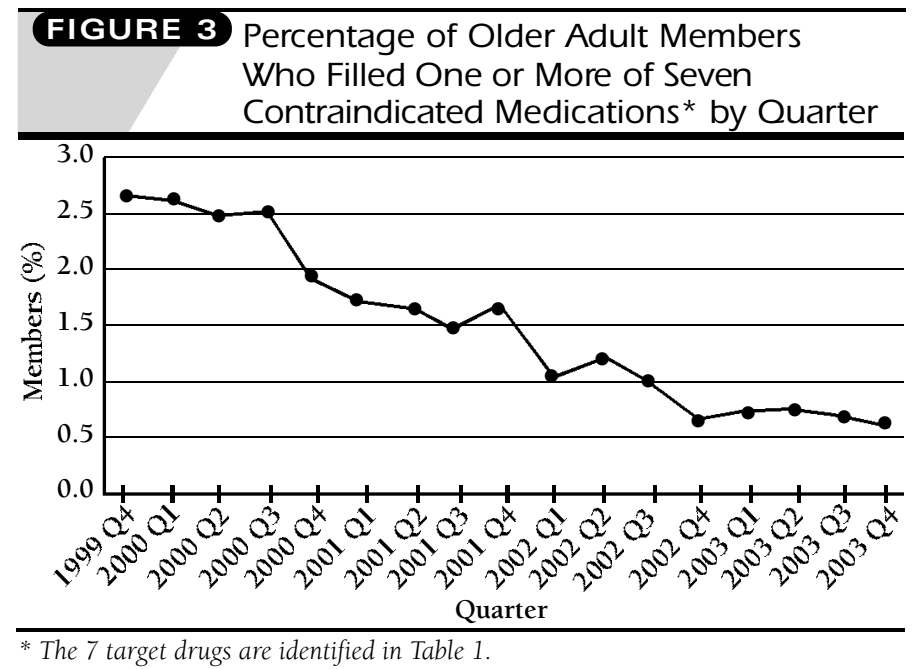


medication was propoxyphene (Table 4). Throughout the first 2 years of the intervention program, propoxyphene use was declining. We therefore removed it from the target drug list and added dicyclomine and disopyramide.

During the interventions, it appeared that, for drug classes where there are a lot of choices without the potential for significant side effects in the older adult population, changing therapy is easier. In classes where there are limited choices, such as skeletal muscle relaxants or gastrointestinal anticholinergics/antispasmodics, it is much more difficult for prescribers to change therapy. Since all skeletal muscle relaxants can cause sedation, older patients prescribed this class of medications should be carefully monitored to prevent adverse events if the drug(s) cannot be changed.

The main program barrier was access to physicians, which hindered physician education. During pharmacy case management, it became apparent that, although the program letter described and referenced medical literature citations on the explicit criteria used for determining potentially inappropriate medications in older patients, prescribers were not cognizant of this information. Additionally, some prescribers were reluctant to believe that criteria even existed. Through pharmacy case management, prescriber education was conducted regarding age-related pharmacokinetic and pharmacodynamic changes in older patients. Some prescribers were resistant to the HMO or a clinical pharmacist assessing the care provided to their patients. Additionally, there appeared to be some association between the reluctance to change therapy and the number of years a physician had been practicing. This may be due to prescriber familiarity and experience with the older drugs. Provider satisfaction with this intervention program has not been measured.

This intervention program, operated primarily by the pharmacy department, enjoyed some benefit from collaborating with the Peer Review Committee in the Quality Risk Department. The collaboration appeared to motivate some prescribers to discuss their patients' medications with the pharmacy case manager in order to avoid interaction with the Peer Review Committee (in the Quality Risk Department).

A secondary outcome of this intervention program was review of the complete medication profile for some patients, potentially uncovering other opportunities for quality improvement in medication management. We did not measure the magnitude of this secondary benefit, but anecdotal comments from physicians suggested that the interventions precipitated reevaluation of the patient's entire drug use.

\section{Limitations}

Our study was a before-after comparison and involved no control group. Our trend analyses in the reduction of older adult patients who received contraindicated drugs were affected by 2 important changes. First, the list of target drugs was revised at the midpoint of the measurement period in $2002 \mathrm{Q} 1$ to delete propoxyphene and its combinations, add dicyclomine
(TABLE $4 \longdiv { \text { Top Three Contraindicated Medications } }$ by Prescription Volume

\begin{tabular}{l|l|l|l}
\hline $\begin{array}{l}\text { Measurement } \\
\text { Period }\end{array}$ & Most Common & \multicolumn{1}{|c}{$\begin{array}{c}\text { 2nd } \\
\text { Most Common }\end{array}$} & \multicolumn{1}{|c}{$\begin{array}{c}\text { Mrd } \\
\text { Most Common }\end{array}$} \\
\hline 2000 Q1 & Amitriptyline & Propoxyphene & Cyclobenzaprine \\
\hline 2000 Q2 & Amitriptyline & Propoxyphene & Cyclobenzaprine \\
\hline 2000 Q4 & Amitriptyline & Propoxyphene & Cyclobenzaprine \\
\hline 2001 Q1 & Amitriptyline & Propoxyphene & Cyclobenzaprine \\
\hline 2001 Q2 & Amitriptyline & Propoxyphene & Cyclobenzaprine \\
\hline 2001 Q4 & Amitriptyline & Propoxyphene & Cyclobenzaprine \\
\hline 2002 Q1* & Amitriptyline & Propoxyphene & Cyclobenzaprine \\
\hline 2002 Q2 & Amitriptyline & Cyclobenzaprine & Diazepam \\
\hline 2002 Q4 & Cyclobenzaprine & Methocarbamol & Diazepam \\
\hline 2003 Q1 & Cyclobenzaprine & Indomethacin & Methocarbamol \\
\hline 2003 Q2 & Cyclobenzaprine & Indomethacin & Diazepam \\
\hline 2003 Q3 & Cyclobenzaprine & Methocarbamol & Diazepam \\
\hline 2003 Q4 & Cyclobenzaprine & Diazepam & Methocarbamol \\
\hline
\end{tabular}

* Criteria changed according to Zhan et al. (Zhan C, Sangl J, Bierman AS, et al. Potentially inappropriate medication use in the community-dwelling elderly. JAMA 2001;286:2823-29), including removal of proxpoxyphene and combinations from target drugs (Table 1) and definition of amitriptyline as appropriate in doses of $50 \mathrm{mg}$ or less.

and disopyramide, and change the screen for amitriptyline use to only those doses above $50 \mathrm{mg}$ per day. Second, the denominator for our primary measure was changed in the last year of the 4-year measurement period to include commercial HMO members as well as Medicare + Choice members. This was associated with a small but noticeable increase in our primary measure from $0.6 \%$ of patients who received 1 or more of the 7 target drugs to $0.7 \%$ of patients (Table 3 ).

Although the interventions were aimed at decreasing inappropriate prescribing of one or more contraindicated medications in our patient population, we did not measure the impact of the interventions on health care resource utilization or patient outcomes. We assumed that decreasing inappropriate medication use in an older adult population may have a favorable effect on patient outcomes.

This intervention involved collaboration between the Pharmacy Services Department and the Quality Risk Department where Pharmacy Services provided the list of target prescribers and patients to the Quality Risk Department after the end of each calendar quarter. Once the Quality Risk Department received this information, prescribers were not always immediately contacted by letter within the next calendar quarter. In other words, a given prescriber may not have been contacted by the Quality Risk Department regarding the target drug and patient within weeks of the close of the previous calendar quarter. Prescriber contact became timelier in the latter years of the intervention. 


\section{APPENDIX Intervention Letter to Primary Care Physician}

$<<$ MD NAME $>>$, MD

$<<$ DATE $>>$

$<<$ MD ADDRESS l $>>$

$<<$ MD ADDRESS l $>>$

$<<$ MD CITY, STATE, ZIP $>>$

Dear Primary Care Provider,

Trends from the NCHS (1985-1999) show that there was a 22\% increase in the rate of office visits for patients over 65 years of age. Four or more drugs were provided or prescribed more often for patients > 65 years of age, compared to office visits for all other age groups. Patients $>65$ years of age were $558 \%$ more likely to have an NME (new molecular entity) mentioned at their office visit compared to the youngest age group. This is disturbing considering many NMEs are not studied in this older patient population. ${ }^{1}$

Prescribing certain medications represents an area of concern in the delivery of medical care, especially regarding elderly patients. Studies indicate that geriatric patients are at high risk for developing complications due to inappropriate medication prescribing which may result in serious drug-related morbidity or may lead to drug-related mortality. Explicit criteria have been developed through literature and consensus methodology for delineating what constitutes inappropriate use of medications in the elderly. These criteria target medications that should always be avoided, are rarely appropriate, may have some indications for use, as well as recommendations concerning dosages and duration of drug therapies that should not be exceeded..$^{2-5}$ In 2002 , we revised our list of medications which may be potentially inappropriate to use in the elderly.

We have enclosed a list of your patients who received or continue to receive these "potentially inappropriate" medications. Physicians who continue to prescribe these "potentially inappropriate" drugs will be evaluated by our Quality Risk Management Department. We encourage you to evaluate the enclosed member's medications and prescribe an alternative from our formulary If you should have any questions or comments, please call Michele B. Kaufman, Pharm.D. at (646) 447-7192.

Sincerely,

Ronald I. Platt, M.D.

Senior Vice President

Chief Medical Officer

cc: Prescribing Physician

References

1. CDC/NCHS. U.S. Department of Health E Human Services. July 2001.

2. Aparasu R, Fliginger S. Inappropriate medication prescribing for the elderly by office-based physicians. Ann Pharmacother. 1997;31:823-29.

3. Beers M. Explicit criteria for determining potentially inappropriate medication use by the elderly. Arch Intern Med. 1997;157:1531-36.

4. Futterman R, Fillit H, Roglieri JL, et al. Use of ineffective or unsafe medications among members of Medicare HMO compared to individuals in a Medicare Fee-ForService Program. Am J Manag Care. 1997;3:569-75.

5. Zhan C, Sangl J, Bierman AS, et al. Potentially inappropriate medication use in the community-dwelling elderly. JAMA. 2001;286:2823-29.

\section{Conclusions}

Over a 4-year measurement period, our quality improvement intervention with prescribers of target drugs contraindicated in older adults demonstrated that the percentage of target prescriptions and the percentage of patients who receive target drugs can both be reduced. While the incidence of use of contraindicated drugs can be reduced, a goal of zero incidence of prescribing of drugs judged to be inappropriate in older adults may be unattainable.

\section{ACKNOWLEDGMENTS}

We would like to acknowledge the statistical assistance of Beatriz Jaramillo, DrPH; Joyce Co, MPH; and Jacqueline Arciniega, MPH, of the Health Services Analysis Unit of HIP Health Plan of New York.

\section{DISCLOSURES}

No outside funding supported this research. Authors Michele B. Kaufman, Kaliroi Alimonos Brodin, and Araksi Sarafian disclose no potential bias or conflict of interest relating to this article.

Kaufman served as principal author of the study. Study concept and design, analysis and interpretation of data, and drafting of the manuscript and its critical revision were the work of all authors.

\section{REFERENCES}

1. Clinical Pharmacology, Section 22. Drug Therapy in the Elderly, chapter 304. In: Beers MH, Berkow R, eds. The Merck Manual of Diagnosis ad Therapy. 17th ed. Rahway, NJ; Merck Publishing Group, Merck \& Co., Inc.; March 1999. Available at: http://www.merck.com/pubs/mmanual/section22/chapter304/304a.html. Accessed July 15, 2003.

2. Zhan C, Sangl J, Bierman AS, et al. Potentially inappropriate medication use in the community-dwelling elderly. JAMA. 2001:286:2823-29. 
3. Ensrud KE, Blackwell TL, Mangione CM, et al. Central nervous systemactive medications and risk for falls in older women. J Am Geriatr Soc. 2002;50:1629-37.

4. Steinweg KK. The changing approach to falls in the elderly. Am Fam Physician. 1997;56:1815-23.

5. DeBisschop M, Oliphant CM. Medication use and falls in elderly patients. US Pharm. 1999;11:98-103.

6. Schneider JK, Mion LC, Frengley JD. Adverse drug reactions in an elderly outpatient population. Am J Health Syst Pharm. 1992;49:90-96.

7. Aparasu RR, Fliginger SE. Inappropriate medication prescribing for the elderly by office-based physicians. Ann Pharmacother. 1997;31:823-29.

8. Aparasu RR, Sitzman SJ. Inappropriate prescribing for elderly outpatients. Am J Health Syst Pharm. 1999;56:433-39.

9. Beers MH. Explicit criteria for determining potentially inappropriate medication use by the elderly. Arch Intern Med. 1997;157:1531-36.

10. Willcox SM, Himmelstein DU, Woolhandler S. Inappropriate drug prescribing for the community-dwelling elderly. JAMA. 1994;272:292-96.

11. Stuck AE, Beers MH, Steiner A, et al. Inappropriate medication use in community-residing older persons. Arch Intern Med. 1994;154:2195-2200.
12. Goulding MR. Inappropriate medication prescribing for elderly ambulatory care patients. Arch Intern Med. 2004;164:305-12.

13. Curtis LH, Ostbye T, Sendersky V, et al. Inappropriate prescribing for elderly Americans in a large outpatient population. Arch Intern Med. 2004; 164:1621-25

14. United States General Accounting Office Report. Prescription drugs and the elderly: many still receive potentially harmful drugs despite recent improvements, July 1995. GAO/HEHS-95-152.

15. Kaufman MB. Inappropriate prescribing in the elderly. In: HIP Pharmacy \& Therapeutics Newsletter.Vol. 7, No. 1 [Winter 2001]:3-5.

16. MacKinnon NJ, Hepler CD. Preventable drug-related morbidity in older adults. 1. Indicator development. J Manag Care Pharm. 2002;8(5):365-71.

17. MacKinnon NJ, Hepler CD. Indicators of preventable drug-related morbidity in older adults. 2. Use within a managed care organization. J Manag Care Pharm. 2002;9(2):134-41.

18. Fick DM, Waller JL, Maclean JR, et al. Potentially inappropriate medication use in a Medicare managed care population: association with higher costs and utilization. J Manag Care Pharm. 2001;7(5):407-13.

19. Fick DM, Cooper JW, Wade WE, et al. Updating the Beers Criteria for Potentially Inappropriate Medication Use in Older Adults—results of a US consensus panel of experts. Arch Intern Med. 2003;163:2716-24. 